\begin{tabular}{|c|c|c|}
\hline \multirow{2}{*}{$2 /$} & $\begin{array}{l}\text { Науковий вісник НлтУ України } \\
\text { Scientific Bulletin of UNFU }\end{array}$ & $\begin{array}{l}\text { ISSN } 1994-7836 \text { (print) } \\
\text { ISSN 2519-2477 (online) }\end{array}$ \\
\hline & http://nv.nltu.edu.ua & (C) (1) \\
\hline$H$ & https://doi.org/10.15421/40280231 & $@ \square$ Correspondence author \\
\hline & $\begin{array}{l}\text { Article received 02.03.2018 p. } \\
\text { Article accepted 29.03.2018 p. }\end{array}$ & $\begin{array}{r}\text { D.P. Rebot } \\
\text { dasha_kotlyarova@ukr.net }\end{array}$ \\
\hline & УДк 621.9.048.6 & \\
\hline
\end{tabular}

Д. П. Ребот, В. Г. Топільницький

Національний університет "Львівська політехніка", м. Львів, Україна

\title{
МАТЕМАТИЧНА МОДЕЛЬ ВИЗНАЧЕННЯ ЗМІНИ АМПЛІТУДИ ТА ЧАСТОТИ КОЛИВАННЯ СИПКОГО МАТЕРІАЛУ В ПРОЦЕСІ ВІБРОСЕПАРАЦІЇ
}

Розглянуто останні розробки вібраційних сепараторів, їх переваги та дослідження, які проводили у сфері вібраційної сепарації. Встановлено, що проведені на сьогодні дослідження не можуть повністю описати рух сипкого матеріалу під час його вібраційної сепарації. Запропоновано метод визначення та дослідження амплітуди та частоти коливань сипкого матеріалу під час його сепарації за умови, що матеріал, який сепарується, рухається вздовж сита із певною сталою швидкістю, а нелінійні пружні характеристики сипкого матеріалу описуються певною степеневою залежністю. Для побудови математичної моделі руху матеріалу вздовж сита використано методи нелінійної механіки та апарат спеціальних Аteb-функцій. Під час дослідження знайдено співвідношення, які дають змогу визначити зміни амплітуди та частоти сипкого матеріалу залежно від швидкості його руху вздовж сита вібраційного сепаратора та від його фізико-механічних характеристик. Отримано аналог рівнянь у стандартному вигляді, які описують закони зміни основних параметрів динамічного процесу руху сипкого матеріалу вздовж сита. На основі отриманих результатів встановлено, що для найпростішої моделі процесу сепарації частота динамічного процесу залежить від амплітуди і швидкості руху середовища вздовж сита та для більших значень швидкості переміщення вздовж сита частота коливань сипкого середовища $є$ меншою.

Ключові слова: математична модель; вібраційний сепаратор; сипкий матеріал; фізико-механічні характеристики; динамічний процес.

Вступ. Вібраційна сепарація відіграє важливу роль у процесах виробництва продукції у різних галузях промисловості. Це спонукає до створення нових установок та проведення досліджень для підвищення ефективності процесу сепарації. Вібраційні сортувальні машини, вібросита, грохоти та вібраційні екрани на сьогодні розробляють багато виробників. Найвідоміші з них - SWECO, VIBROWEST, CUCCOLINI, Pilot Crushes, WS Tyler (Technology news, 2011). Ці сепаратори можуть розділяти частинки розміром від кількох сантиметрів до десятих частин мікрометра, що дає змогу отримати на виході продукцію із бажаною гранулометричною чистотою.

Перевагами сучасних вібросепараторів є можливість швидкої заміни та очищення сит, висока ефективність сепарації, відсутність передачі вібрацій на конструкцію завдяки наявності ефективних пружних підвісок, компактність, поширення та регулювання вібрацій як у горизонтальному, так і вертикальному напрямках, яке досягається за рахунок противаг, що встановлені на кінцях вала двигуна. Зміщення верхньої противаги створює вібрацію в горизонтальній площині та дає змогу переміщувати матеріал вздовж сита, а зміщення нижньої противаги створює вібрації у вертикальній та дотичних площинах. Також конструкції вібраційних двигунів дають змогу легко регулювати противаги та

змінювати вібрацію таким чином, щоб знайти оптимальний метод для сепарації матеріалу, зменшення часу та збільшення ефективності сепарації (рис. 1).

На ефективність сепарації впливають не тільки конструктивні характеристики вібросепаратора, але i якість продукції, яка сепарується, зокрема ії̈ гранулометричний склад та цілісність. Тому важливо проводити дослідження не тільки конструкції вібросепаратора, але й взаємозв'язку та взаємовпливу сепаруючої установки та сипкого матеріалу в процесі сепарації. Зокрема, враховуючи, що сипкий матеріал здійснює на ситі складний просторовий рух, від якого теж залежить ефективність сепарації, доцільно провести детальніші дослідження у цій сфері. На жаль, такий рух неможливо описати однією чи кількома залежностями, тому на сьогодні розглядають окремі випадки руху матеріалу на ситі (Zheng Wang, 2016; Lapshyn, 2015; Xiaodong Yu, 2017), де рух матеріалу моделюється переважно як рух окремої частинки. Інший випадок руху сипкого матеріалу - це рух, де матеріал моделюється як нашарування плоских, пружно пластичних балок, що контактують між собою та зі стінками контейнера сепаратора. Окремі випадки руху за вказаної вище гіпотези розглядали (Topilnytskyy, 2014, 2017; Stotsko, 2013, 2016) за умови повздовжніх та поперечних коливань контейнера сепа-

\section{Інформація про авторів:}

Ребот Дарія Петрівна, канд. техн. наук, асистент кафедри проектування та експлуатації машин. Email: dasha_kotlyarova@ukr.net

Топільницький Володимир Григорович, канд. техн. наук, доцент кафедри проектування та експлуатації машин. Email: topilnvol@gmail.com

Цитування за ДСТУ: Ребот Д. П., Топільницький В. Г. Математична модель визначення зміни амплітуди та частоти коливання сипкого матеріалу в процесі вібросепарації. Науковий вісник НЛтУ України. 2018, т. 28, № 2. С. 164-167.

Citation APA: Rebot, D. P., \& Topilnytskyy, V. G. (2018). Mathematical Model for Determination of Amplitude and Frequency Changing of Granular Material in the Vibratory Separation Process. Scientific Bulletin of UNFU, 28(2), 164-167.

https://doi.org/10.15421/40280231 
ратора. Проведені дослідження описують тільки загальну поведінку шару матеріалу у вібруючому контейнері та потребують детальнішого розгляду та вдосконалення. Тому важливою задачею $є$ продовжити попередні дослідження та побудувати математичну модель визначення амплітуди та частоти сипкого матеріалу залежно від його фізико-механічних характеристик, швидкості руху вздовж сита, що в подальшому дасть змогу оптимізувати ефективність сепарування.

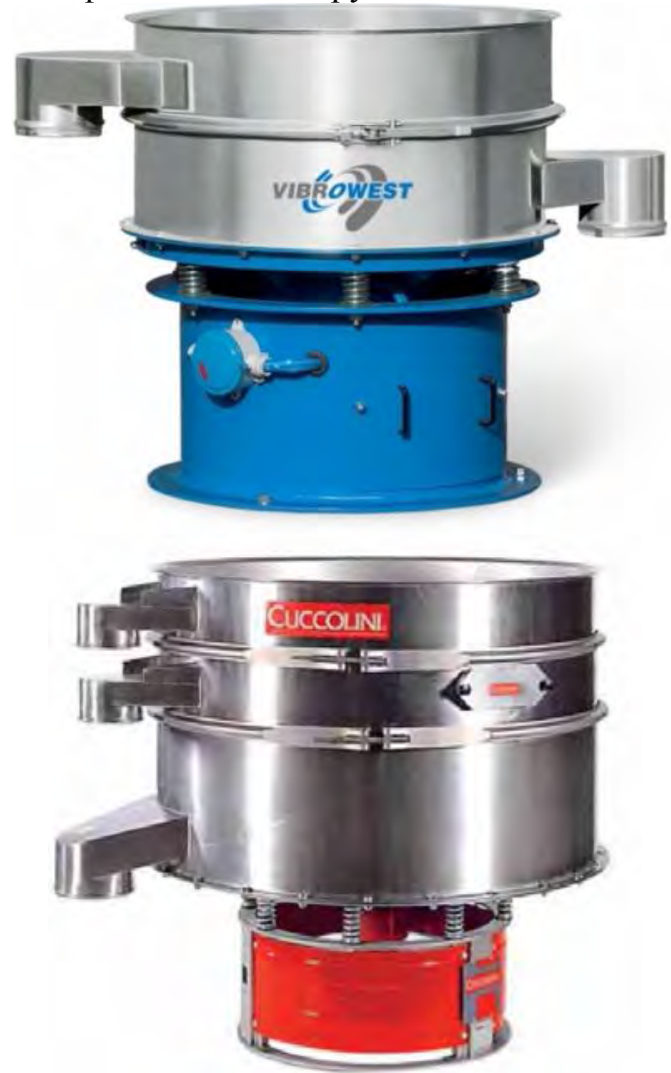

Рис. 1. Вібросепаратори італійських фірм VIBROWEST та CUCCOLINI

Матеріал та методи дослідження. Найпоширенішими сепараторами у промисловості є решітчасті вібраційні сепаратори. Такий тип конструкції дає змогу провести оптимальну сепарацію сипкого матеріалу за його гранулометричним складом та фізико-механічними показниками. Вважатимемо, що в процесі сепарації шар матеріалу рухається вздовж сита та контактує зі стінками контейнера пружно або як шарнірно закріплена балка (Topilnytskyy, 2014). При цьому коливання вважаються консервативними та нелінійні пружні характеристики матеріалів приймаються певною степеневою залежністю. У взятій за основу консервативній системі амплітуда коливань не залежить від часу, тому що періодичне збурення у нерезонансному випадку не зумовлює у першому наближенні зміни амплітуди коливань. Такий тип коливань дає змогу визначити вплив швидкості руху сипкого матеріалу вздовж сита та нелінійних сил тертя на процес вібросепарації.

За умови одночастотного періодичного збурення матеріалу, який сепарується, побудовано математичну модель із застосуванням періодичних Ateb-функцій. У нерезонансному випадку коливань динамічний процес матиме вигляд

$$
u_{k}(x, t)=a X_{k}(x) c a\left(v+1,1, \omega_{k}(a) t+\theta\right),
$$

де: $u_{k}(x, t)$ - переміщення довільного перерізу шару сипкого матеріалу; $a$ - амплітуда коливань сипкого матеріалу; $\omega_{k}$ - власна частота коливань сипкого матеріалу, $\omega_{k}(a)+a \frac{d \omega_{k}(a)}{d a}=\frac{v+2}{2} \omega_{k}(a) ; \theta-$ фаза коливань сипкого матеріалу.

За умови збурення рівняння відносного руху матеріалу вздовж сита в довільний момент часу матиме вигляд

$$
\frac{\partial u_{k}(x, t)}{\partial t}=-\frac{2 a}{v+2} \omega_{k}(a) X_{k}(x) s a\left(1, v+1, \omega_{k}(a) t+\theta\right) .
$$

3 використанням методу Ван-дер-Поля для диференціальних рівнянь із малим параметром рівняння, яке описує процес вібраційної сепарації сипкого матеріалу, матиме вигляд

$$
\begin{gathered}
\frac{\partial^{2} u_{k}(x, t)}{\partial t^{2}}-\alpha^{2} \frac{\partial^{2} u_{k}(x, t)}{\partial x^{2}}\left(\frac{\partial u_{k}(x, t)}{\partial x}\right)^{v}= \\
=\varepsilon \bar{f}\left(x, \frac{\partial u_{k}(x, t)}{\partial x}, \frac{\partial u_{k}(x, t)}{\partial t}\right)-2 V \frac{\partial^{2} u_{k}(x, t)}{\partial x \partial t}-V^{2} \frac{\partial^{2} u_{k}(x, t)}{\partial x^{2}}
\end{gathered}
$$

У випадку неконсервативних коливань амплітуда коливань шару сипкого матеріалу $a$ та фаза коливань $\theta \in$ функціями часу. Швидкість руху матеріалу вздовж сита приймається сталою величиною, яка визначається способом подачі матеріалу на сито, кутом нахилу сита, його структурою та ін. 3 урахуванням цього, продиференціювавши рівняння (3) по $t$, отримаємо:

$$
\begin{gathered}
\frac{\partial u_{k}}{\partial t}=X_{k}(x)\left\{\frac{\partial a}{\partial t} c a(k)-\frac{2 a}{v+2}\left(\omega_{k}+\frac{\partial \theta}{\partial t}\right) s a\left(1, v+1, \psi_{k}\right)\right\}, \\
\frac{\partial^{2} u}{\partial t^{2}}=-\frac{2 X_{k}}{v+2} \frac{\partial a}{\partial t}\left(\omega_{k}+a \frac{d \omega_{k}}{d a}\right) s a\left(1, v+1, \psi_{k}\right)+ \\
+\frac{2 X_{k}}{v+2} a \omega_{k}\left(\omega_{k}+\frac{\partial \theta}{\partial t}\right) c a^{v+1}\left(v+1,1, \psi_{k}\right), \\
\psi_{k}=\omega_{k}(a) t+\theta .
\end{gathered}
$$

Залежність (4) описує динамічний процес у збуреному випадку, тоді в кінцевому результаті амплітуда і фаза коливань визначаються із системи звичайних диференціальних рівнянь:

$$
\begin{aligned}
& \frac{\partial a}{\partial t}=\frac{\varepsilon s a\left(1, v+1, \psi_{k}\right) f_{1}^{*}\left(a, \psi_{k}\right)}{\mathrm{P}\left[g_{k}+\frac{2}{v+2}\left(\omega_{k}+a \frac{d \omega_{k}}{d a}\right) s a^{2}\left(1, v+1, \psi_{k}\right)\right]} ; \\
& \frac{\partial \theta}{\partial t}=\frac{(v+2) c a\left(v+1,1, \psi_{k}\right)\left[\varepsilon f_{1}^{*}\left(a, \psi_{k}\right)-\frac{v+2}{3 v+4}\left(\frac{k \Pi_{x}}{l}\right)^{2} V^{2} a\right]}{2 \mathrm{P} a\left[g_{k}+\frac{2}{v+2}\left(\omega_{k}+a \frac{d \omega_{k}}{d a}\right) s a^{2}\left(1, v+1, \psi_{k}\right)\right]},
\end{aligned}
$$

де $g_{k}=\omega_{k} c a^{v+2}\left(v+1,1, \psi_{k}\right)$

Тобто в кінцевому варіанті отримуємо у параметризованій формі два звичайні диференціальні рівняння, які описують закон зміни амплітудо-частотних показників від зовнішніх i внутрішніх характеристик взаємовпливу робочого контейнера та сипкого матеріалу. Отриманий результат показує, що для найпростішої моделі процесу сепарації частота динамічного процесу залежить від амплітуди та швидкості руху середовища вздовж сита. До того ж для більших значень швидкості переміщення вздовж сита частота коливань сипкого середовища $\epsilon$ меншою.

На рис. 2 показано зміну частоти коливань шару сипкого матеріалу залежно від швидкості його руху вздовж сита та параметра, що враховує фізико-механічні параметри матеріалу. 


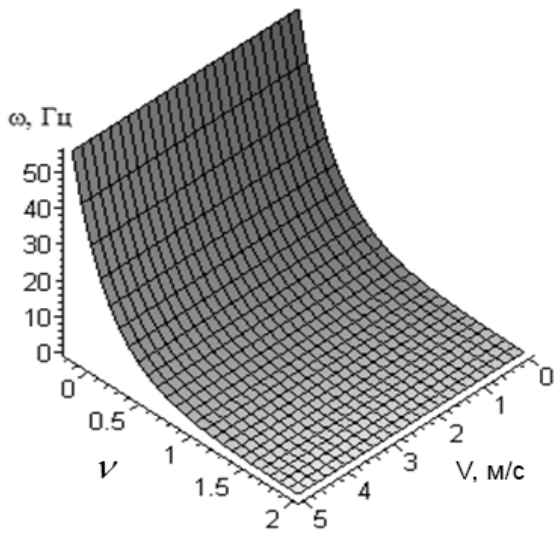

Рис. 2. Вплив параметра $v$ та швидкості руху шару матеріалу на його частоту коливання за умови, що $a=0,01 \mathrm{~m}, l=1 \mathrm{м}$

За побудованою графічною залежністю можна визначити, що із зростанням швидкості руху сипкого матеріалу вздовж сита його частота коливань зменшується.

Результати дослідження. Отримана математична модель дає змогу визначити зміну амплітуди та частоти сипкого матеріалу. Зважаючи на те, що сепарація матеріалу відбувається за складним законом, то ці дослідження можуть бути базою для подальших досліджень та визначення оптимальних амплітудо-частотних показників матеріалів, які сепаруються, для підвищення ефективності сепарації. Також математичну модель можна використати під час досліджень процесів вібротранспортування та віброоброблення матеріалів.

\section{Перелік використаних джерел}

Lapshyn, V. L., Rydyh, A. V., \& Glyhov, A. V., (2015). Matematicheskoe modelirovanie procesa vibracionnogo dvigeniia chastici materiala po rabochemy organy separatora. [Mathematical modeling of the vibrational movement process of the particle material on the work unit of the separator]. Scientific Bulletin of Irkutsk State Technical University, 3(98), 49-55. [in Russian].

Stotsko, Z., Rebot, D., \& Topilnytskiy, V. (2016). Modeling and optimization of the parameters of loose environment vibratory separation. Scientific Journal Technological Complexes, 1(13), 86-90.

Stotsko, Z., Topilnytskyj, V., \& Rebot, D. (2013). The influence of the loose medium parameters on the process of vibratory separation. Journal of Manufacturing and Industrial Engineering, 1-2(13), 1719. https://doi.org/10.12776/mie.v12i1-2.179

Technology news. (2011). Sweco introduces high rate separator. Filtration $+\quad$ Separation, 48(5), 10-13. https://doi.org/10.1016/S0015-1882(11)70191-4

Topilnytskyy, V. G., Stotsko, Z. A., Kysyj, J. M., \& Rebot, D. P. (2014). Investigation of the dynamics of vibratory separator with unbalanced drive. Scientific Bulletin of NULP, 786, 53-65.

Topilnytskyy, V., Rebot, D. et al. (2017). Modeling the dynamics of vibratory separator of the drum type with concentric arrangement of sieves. Eastern-European Journal of Enterprise Technologies, 2/7(86), 26-34. https://doi.org/10.15587/1729-4061.2017.95615

Wang, Z., Miles, N. J., Wu, Tao, Gu, Fu, \& Hall, Ph. (2016). Recycling oriented vertical vibratory separation of copper and polypropylene particles. Powder Technology, 301, 694-700. https://doi.org/10.1016/i.powtec.2016.06.003

Yu, Xiaodong, Luo, Zhenfu, Li, Haibin, \& Gan, Deqing. (2017). Effect of vibration on the separation efficiency of oil shale in a compound dry separator. Fuel, 214, 242-253. https://doi.org/10.1016/j.fuel.2017.10.129

Д. П. Ребот, В. Г. Топильницкий

Национальный университет "Львовская политехника", г. Львов, Украина

\title{
МАТЕМАТИЧЕСКАЯ МОДЕЛЬ ОПРЕДЕЛЕНИЯ ИЗМЕНЕНИЯ АМПЛИТУДЫ И ЧАСТОТЫ КОЛЕБАНИЯ СЫПУЧИХ МАТЕРИАЛОВ В ПРОЦЕССЕ ВИБРОСЕПАРАЦИИ
}

\begin{abstract}
Рассмотрены последние разработки вибрационных сепараторов, их преимущества и исследования, проводимые в сфере вибрационной сепарации. Установлено, что проведенные исследования не могут полностью описать движение сыпучего материала во время его вибрационной сепарации. Предложен метод определения и исследования амплитуды и частоты колебаний сыпучего материала во время его сепарации при условии, что материал, который сепарируется, движется вдоль сита с определенной постоянной скоростью, а нелинейные упругие характеристики сыпучего материала описываются определенной степенной зависимостью. Для построения математической модели движения материала вдоль сита использованы методы нелинейной механики и аппарат специальных Ateb-функций. В ходе исследования найдены соотношения, которые позволяют определить изменения амплитуды и частоты сыпучего материала в зависимости от скорости его движения вдоль сита вибрационного сепаратора и от его физико-механических характеристик. Получен аналог уравнений в стандартном виде, которые описывают законы изменения основных параметров динамического процесса движения сыпучего материала вдоль сита. На основе полученных результатов установлено, что для простейшей модели процесса сепарации частота динамического процесса зависит от амплитуды и скорости движения среды вдоль сита и для больших значений скорости перемещения вдоль сита частота колебаний сыпучей среды меньше.
\end{abstract}

Ключевые слова: математическая модель; вибрационный сепаратор; сыпучий материал; физико-механические характеристики; динамический процесс.

D. P. Rebot, V. G. Topilnytskyy

Lviv Polytechnic National University, Lviv, Ukraine

\section{MATHEMATICAL MODEL FOR DETERMINATION OF AMPLITUDE AND FREQUENCY CHANGING OF GRANULAR MATERIAL IN THE VIBRATORY SEPARATION PROCESS}

The effectiveness of the vibration separation process is known to be influenced by both the design of the vibration separator, and also by the characteristics of the material being separated. The amplitude and frequency of oscillations of the material along the screen separator also influence. However, considering that the loose material carries out a complex spatial movement, it can't be described by one equation or a system of equations. Therefore, different cases of movement of the material on the screen are considered, where the loose material is modelled as a particle, plate, or plate layers. The authors propose a method for determining and investigating the amplitude and frequency of oscillations of bulk material during its separation, providing that the material that is separated moves along the screen with a certain steady speed, its oscillations are conservative, and the nonlinear elastic characteristics of the bulk material are described by certain degree dependence. Methods of nonlinear mechanics and the apparatus of special Ateb-functions are used to construct a mathematical model of motion of a material along a screen. During the investigations we have found correlations that allow determining changes in the amplitude and frequency of the bulk material depending on its velocity along the screen of the vibration separator and its physical and mechanical characteristics. We have also determined that such equations are rather complex in comparison with, for example, the quasi-linear model of the dynamics of material motion because in this case the frequency of oscillation of a material depends on its amplitude.

Keywords: mathematical model; vibration separator; loose material; physical-mechanical characteristics; dynamical process. 